\title{
Avaliação da atividade antibacteriana e prospecção fitoquímica de Solanum paniculatum Lam. e Operculina hamiltonii (G. Don) D. F. Austin \& Staples, do semi- árido paraibano
}

\begin{abstract}
LÔBO, K.M.S. ${ }^{\text {; }}$ ATHAYDE, A.C.R. ${ }^{2}$; SILVA, A.M.A. ${ }^{3}$; RODRIGUES, F.F.G. ${ }^{4}$; LÔBO, I.S. ${ }^{5}$; BEZERRA, D.A.C. ${ }^{1}$; COSTA, J.G.M. ${ }^{4 *}$

${ }^{1}$ Programa de Pós-Graduação em Zootecnia, Universidade Federal de Campina Grande, Av. Universitária, s/n, Santa Cecília, Caixa Postal 64, CEP: 58700-970, Patos-Brasil katiusciax@gmail.com; biologace@hotmail.com ${ }^{2}$ Unidade Acadêmica de Ciências Biológicas/CSTR da Universidade Federal de Campina Grande, CEP: 58700970, Patos-Brasil athayde@cstr.ufcg.edu.br ${ }^{3}$ Unidade Acadêmica de Medicina Veterinária, CSTR da Universidade Federal de Campina Grande, CEP:58700-970, Patos-Brasil aderbal@cstr.ufcg.edu.br ${ }^{4}$ Universidade Regional do Cariri - URCA, Programa de Pós-Graduação em Bioprospecção Molecular, Laboratório de Pesquisas de Produtos Naturais, CEP: 63105.000, Crato-Brasil fabiolafer@gmail.com ${ }^{5}$ Saúde Pública, Universidade Regional do Cariri, CEP:63105.000, Crato-Brasil inalzuir@yahoo.com.br *galberto.martins@gmail.com
\end{abstract}

\begin{abstract}
RESUMO: Devido ao aparecimento de populações de parasitos resistentes, as drogas farmacêuticas, alternativas de controle, estão sendo pesquisadas utilizando plantas medicinais. O objetivo deste estudo foi avaliar a atividade antibacteriana e realizar a análise fitoquímica do extrato etanólico de duas espécies do semi-árido paraibano, Solanum paniculatum Lam. e Operculina hamiltonii (G. Don) D. F. Austin \& Staples. As referidas espécies são muito utilizadas pela população rural contra verminoses gastrintestinais de ovinos. A prospecção fitoquímica foi obtida a partir dos extratos etanólicos para análise dos constituintes químicos existentes nas duas espécies. As análises dos extratos indicaram a presença de taninos flobabênicos, flavononóis, flavononas e alcalóides em ambas as espécies. A atividade antibacteriana foi determinada inicialmente pelo método de difusão em cavidade. A espécie $S$. paniculatum apresentou atividade contra Staphylococcus aureus (ATCC 12692), Escherichia coli (ATCC 25922) e Pseudomonas aeruginosa (ATCC 15442), no entanto $O$. hamintonii não demonstrou atividade contra as linhagens bacterianas testadas.
\end{abstract}

Palavras-chave: Solanum paniculatum, Operculina hamiltonii, extratos etanólicos, atividade antibacteriana

\begin{abstract}
Evaluation of antibacterial activity and phytochemical prospection of Solanum paniculatum Lam. and Operculina hamiltonii (G. Don) D. F. Austin \& Staples from the semi-arid region of Paraíba State, Brazil. The emergence of resistant parasite populations has led to the study of pharmaceutical drugs, which represent an alternative control. This study aimed to evaluate the antibacterial activity and to perform the phytochemical analysis of the ethanol extract from two species belonging to the semi-arid region of Paraíba State, Brazil: Solanum paniculatum Lam. and Operculina hamiltonii (G. Don) D. F. Austin \& Staples. Such species have been largely used by the rural population against ovine gastrointestinal helminthes. Phytochemical prospection was obtained from ethanol extracts for analysis of chemical compounds present in both species. Extract analyses indicated the presence of condensed tannins, flavonols, flavanones, and alkaloids in both species. The antibacterial activity was initially determined by the cavity method. The species S. paniculatum had activity against Staphylococcus aureus (ATCC 12692), Escherichia coli (ATCC 25922) and Pseudomonas aeruginosa (ATCC 15442); however, O. hamintonii did not present activity against the tested bacterial strains.
\end{abstract}

Key words: Solanum paniculatum, Operculina hamiltonii, ethanol extracts, antibacterial activity

Recebido para publicação em 26/05/09

Aceito para publicação em 21/09/09

Rev. Bras. PI. Med., Botucatu, v.12, n.2, p.227-233, 2010. 


\section{INTRODUÇÃO}

Por longo período, as plantas foram utilizadas para a pesquisa de produtos naturais, a utilização de plantas medicinais na prática tradicional ainda existe entre os povos de todo o mundo e nos últimos anos tem recebido incentivos da própria Organização Mundial de Saúde (WHO, 2002). Na última década se observou intenso estudo acerca de terapias naturais, por muitos fatores econômicos e sociais que vêm colaborando para o desenvolvimento de práticas de saúde pública (WHO, 2002; Albuquerque \& Hanazaki, 2006).

Apesar da grande diversidade de antimicrobianos que agem sobre diversos microrganismos patogênicos, estudos buscam pelo ideal, ou seja, aquele que apresenta maior espectro de ação, menor toxicidade, menor custo e menor indício de resistência bacteriana, haja vista que já existe resistência bacteriana a alguns produtos antimicrobianos (Nascimento et al., 2000; Pazhani et al., 2004). A atividade antimicrobiana desejada pode ser encontrada em espécies de plantas medicinais. A flora brasileira apresenta-se altamente diversificada em espécies que na maioria ainda não foi pesquisada cientificamente quanto à ação antimicrobiana (Simões et al., 2000; Auricchio \& Bacchi, 2003).

Em razão ao grande aumento da resistência de microrganismos patogênicos a múltiplas drogas e devido ao uso indiscriminado de antimicrobianos surge a preocupação para a procura de novas alternativas terapêuticas (Oliveira et al., 2007a). O uso de extratos e componentes químicos vegetais ambos com propriedades antimicrobianas vêm contribuindo para resultado satisfatório em tratamentos terapêuticos (Albuquerque \& Hanazaki, 2006; Oliveira et al., 2007b).

A avaliação do potencial terapêutico de plantas medicinais e de alguns dos constituintes, tais como, flavonóides, alcalóides, triterpenos, sesquiterpenos, taninos e lignanas, tem sido objeto de incessantes estudos (Havsteen, 1983).

O impacto da crescente resistência dos microrganismos a antibióticos e substâncias específicas intensificou a pesquisa para 0 desenvolvimento de novas drogas que sejam capazes de combater as estratégias de adaptação que esses organismos elaboram (Prates et al., 2000). Nas últimas décadas, os fitofármacos têm sido usados como alternativa no meio terapêutico, mediante as propriedades antimicrobianas (Kreuger et al., 2007; Simões et al., 2008).

O conhecimento prévio das classes de componentes químicos encontrados nos vegetais se torna necessário para fornecer a relação dos princípios ativos. Uma vez detectada a presença de determinados grupos químicos, o estudo fitoquímico e biológico é direcionado.
Dentre as inúmeras famílias botânicas que apresentam atividades terapêuticas comprovadas, a família Solanaceae oferece muitas contribuições na medicina e os efeitos de algumas das substâncias vão desde antialérgicos a alucinógenos. A espécie Solanum paniculatum L. conhecida como Jurubeba, Jurupeba, Juripeba, Juvena, Jubeba Juina ou Juna (Mesia-Vela et al., 2002) é muito utilizada na medicina popular contra verminoses gastrintestinais de ovinos (Santos et al., 2007), humanos e no tratamento de icterícia, hepatite crônica e antitérmicos (ForniMartins et al., 1998; Vieira et al., 2008).

Operculina hamiltonii (G. Don) D. F. Austin \& Staples é trepadeira de aspecto ornamental pertencente à família Convolvulaceae, conhecida como batata de purga, Jalapa-brasileira, Jalapa, raizdo-jeticucu e mecoacã (Pereda-Miranda et al., 2003). Essa espécie é utilizada popularmente como purgativa, depurativa do sangue (Martins et al., 2000) e anti-helmíntica (Chagas, 2004; Brito Júnior, 2006; Rodrigues et al., 2007).

Ensaios biológicos avaliam substâncias oriundas de plantas deste gênero, tanto com extratos como com substâncias isoladas. No entanto, ainda são poucas as pesquisas que relatam as propriedades biológicas de espécies vegetais da Caatinga.

Desta forma, tais pesquisas podem favorecer o desenvolvimento e a descoberta de novas drogas vegetais para contribuição significativa no campo da saúde em nível mundial, encontrando substâncias mais eficazes e menos tóxicas contra microrganismos patogênicos e multirresistentes (Barbosa-Filho et al., 2007).

Sabendo-se que a Caatinga apresenta espécies vegetais de grande potencial farmacológico e terapêutico este trabalho objetiva avaliar o potencial antibacteriano, bem como a investigação fitoquímica de S. paniculatum e de O. hamiltonii.

\section{MATERIAL E MÉTODO}

Coleta e identificação do material vegetal As raízes da jurubeba (S. paniculatum) foram coletadas na cidade de Teixeira-PB e as raízes da batata de purga (O. hamiltonii) no Núcleo de Pesquisa para o Trópico Semi-árido (NUPEÁRIDO) do CSTR da UFCG na cidade de Patos, ambas coletadas em junho de 2006. A identificação botânica foi realizada pela Profa Dra Arlene Pessoa da Silva e as exsicatas depositadas no Herbário Caririense Dárdaro de Andrade Lima da Universidade Regional do Cariri, sob os respectivos registros \#4016 e \#3750.

\section{Obtenção dos extratos}

Para a elaboração dos extratos das raízes secas de $S$. paniculatum e $O$. hamiltonii foram 
utilizados $495 \mathrm{~g}$ e $500 \mathrm{~g}$ respectivamente. O material vegetal foi triturado e submerso em etanol absoluto para extração a frio dos constituintes químicos por 72 horas. Os extratos brutos foram obtidos por destilação do solvente em evaporador rotativo obtendo massas finais de 6,10 g e 9,50 g, respectivamente.

\section{Avaliação da atividade antibacteriana}

Para a avaliação da atividade antibacteriana foi realizado inicialmente um screening por difusão em cavidade em concentrações que variaram de $10 \mathrm{a}$ 0,3\% (Bauer, 1966). Foram utilizadas seis culturas padrão, sendo uma Gram-positiva, a Staphylococcus aureus (ATCC 12692) e cinco Gram-negativas, Pseudomonas aeruginosa (ATCC 15442), Escherichia coli (ATCC25922), Proteus vulgaris (ATCC 13315), Shigella flexineri (ATCC 12022) e Klebsiella pneumoniae (ATCC 10031). O teste foi acompanhado por um controle negativo com etanol absoluto $e$ controles positivos com os antibióticos Amicacina (30 $\mu \mathrm{g})$, Cloranfenicol $(30 \mu \mathrm{g})$ e Tetraciclina $(30 \mu \mathrm{g})$.

As linhagens sensíveis ao screening foram avaliadas para determinação da concentração inibitória mínima (CIM) utilizando a metodologia de microdiluição em caldo, com base no documento M7A6 (CLSI/NCCLS) para bactérias. Previamente aos testes, as cepas bacterianas foram ativadas em meio Brain Hear Infusion Broth (BHI) durante 24 horas a 35 $\pm 2^{\circ} \mathrm{C}$. Foram utilizadas três linhagens padrões, sendo uma Gram-positiva, Staphylococcus aureus (ATCC 12692) e duas Gram-negativas, Pseudomonas aeruginosa (ATCC 15442) e Escherichia coli (ATCC 2992). Após este subcultivo, procedeu-se à padronização do inóculo, que consistiu na preparação de uma suspensão bacteriana em $\mathrm{BH}$, cuja turvação fosse similar ao tubo 0,5 da Escala McFarland $\left(1 \times 10^{8}\right.$ UFC mL-1). A seguir, esta suspensão foi diluída a $1 \times 10^{6}$ UFC mL-1 em caldo $\mathrm{BHI}$ a $10 \%$, e volumes de $100 \mu \mathrm{L}$ foram então homogeneizados nos poços de placa de microdiluição acrescido de diferentes concentrações dos extratos de $S$. paniculatum e $O$. hamiltonii, resultando num inóculo final de $5 \times 10^{5} \mathrm{UFC} \mathrm{mL}^{-1}$.

Os extratos foram solubilizados inicialmente em dimetilsufóxido e água destilada (DMSO) de forma a obter-se solução estoque de $103 \mu \mathrm{g} \mathrm{mL}^{-1}$. As concentrações finais das frações no meio de cultura foram 512, 256, 128, 64, 32, 16 e $8 \mu \mathrm{g} \mathrm{mL}^{-1}$. Os testes foram efetuados em triplicata. As placas foram incubadas a $35 \pm 2^{\circ} \mathrm{C}$ durante 24 horas. Como revelador foi utilizado $25 \mu \mathrm{L}$ por poço de resazurina a $0,01 \%$. $\mathrm{O}$ controle negativo foi realizado com o caldo BHI. A concentração inibitória mínima (CIM) foi definida como a menor concentração capaz de inibir completamente o crescimento microbiano, nos poços de microdiluição conforme detectado a olho nu. A leitura dos resultados para determinação da CIM foi considerada como positiva para os poços que permaneceram com a coloração azul e como negativa os que obtiveram coloração vermelha.

\section{Prospecção fitoquímica}

Os extratos brutos foram submetidos a uma série de reações de caracterização fitoquímica para detecção da presença de metabólitos secundários como compostos fenólicos (reação de precipitação com cloreto férrico), naftoquinona (reação ácido/base), caracterização de flavonóides (reação de cianidina e ácido sulfúrico, A-I e A- II), taninos (reação com sais de ferro, precipitação de proteínas, B-I e B-II), cumarinas (observação sob a luz ultravioleta), triterpenos e esteróides (reação de LiebermannBurchard), identificação de heterosídeos cardiotônicos (teste de Baljet e teste de Kedde, C-I e C-II), alcalóides (reação com dragendorff) e caracterização de saponinas (reação de Lieberman-Buchard e o índice de espuma), segundo metodologia descrita por Simões et al. (2000) e Matos (1997).

\section{RESULTADO E DISCUSSÃO}

Os extratos vegetais das duas espécies utilizados no experimento apresentaram atividade antibacteriana (inativação e/ou inibição) seletiva sobre os diferentes inóculos bacterianos utilizados.

A espécie Solanum paniculatum demonstrou melhor atividade contra maior número de microrganismos ensaiados (S. aureus, E. coli e $P$. aeruginosa), bem como, por apresentar valores de CIM, portanto, mais efetivos. Esta maior atividade provavelmente esteja relacionada à grande quantidade de classes alcalóides e taninos presentes neste extrato. Enquanto que a espécie $O$. hamiltonii não apresentou atividades em nenhuma das linhagens avaliadas.

As Tabelas 1 e 2 demonstram os resultados obtidos na avaliação destes extratos e a ação dos antibióticos utilizados.

Foram observados halos de inibição de 12 $\mathrm{mm}$, sendo considerado ativo o extrato de jurubeba nas concentrações 5 e 2,5\%, dados semelhantes ao antibiótico cloranfenicol testado como controle positivo para a cepa de $S$. aureus.

O extrato de $S$. paniculatum na concentração de $10 \%$ apresentou semelhante halo de inibição do crescimento da $E$. coli de frente ao quimioterápico tetraciclina. Também foi comprovado que $S$. flexineri e K. pneumoniae não apresentaram sensibilidade.

Em trabalho com o extrato hidroalcoólico do cajueiro (Anacardium occidentale Linn.), Silva et al. (2007) relataram que houve significante atividade antimicrobiana in vitro sobre as linhagens de $S$. aureus de origem humana hospitalar resistentes (MRSA) e sensíveis a meticilina (MSSA), podendo associar este fato ao tanino existente nesta espécie.

Rev. Bras. PI. Med., Botucatu, v.12, n.2, p.227-233, 2010. 
TABELA 1. Resultados da atividade antibacteriana do extrato etanólico da raiz de S. paniculatum Lam. e $O$. hamiltonii.

\begin{tabular}{|c|c|c|c|c|c|c|c|}
\hline \multirow{3}{*}{ Espécies } & \multirow{3}{*}{$\begin{array}{c}\text { Conc. } \\
\%\end{array}$} & \multicolumn{6}{|c|}{ Microrganismos } \\
\hline & & 1 & 2 & 3 & 4 & 5 & 6 \\
\hline & & \multicolumn{6}{|c|}{ Halos de inibição 24 horas } \\
\hline \multirow{6}{*}{ S.paniculatum } & 10 & $11,66 \pm 0,57$ & $16,33 \pm 4,04$ & ND & $12,33 \pm 2,51$ & ND & ND \\
\hline & 5 & $12,66 \pm 0,57$ & $13,33 \pm 2,51$ & ND & $11,66 \pm 1,57$ & ND & ND \\
\hline & 2,5 & $12 \pm 2,00$ & $12 \pm 1,00$ & ND & $12 \pm 2,64$ & ND & ND \\
\hline & 1,25 & $10,66 \pm 3,79$ & $11,66 \pm 2,08$ & ND & $10 \pm 1,00$ & ND & ND \\
\hline & 0,6 & $7,66 \pm 1,15$ & $11,33 \pm 1,15$ & ND & $8,66 \pm 1,15$ & ND & ND \\
\hline & 0,3 & ND & $8,66 \pm 2,08$ & ND & $7,33 \pm 1,15$ & ND & ND \\
\hline \multirow{6}{*}{ O. hamiltonii } & 10 & ND & ND & ND & ND & ND & ND \\
\hline & 5 & ND & ND & ND & ND & ND & ND \\
\hline & 2,5 & ND & ND & ND & ND & ND & ND \\
\hline & 1,25 & ND & ND & ND & ND & ND & ND \\
\hline & 0,6 & ND & ND & ND & ND & ND & ND \\
\hline & 0,3 & ND & ND & ND & ND & ND & ND \\
\hline
\end{tabular}

1.Staphylococcus aureus; 2.Escherichia coli; 3.Proteus vulgaris; 4.Pseudomonas aeruginosa; 5.Shigella flexineri; 6.Klebsiella pneumoniae. ND:halo de inibição não foi detectável.

TABELA2. Atividade antibacteriana de antibióticos.

\begin{tabular}{ccccc}
\hline & \multicolumn{4}{c}{ Halo de inibição $(\mathrm{mm}$ de diâmetro) } \\
\hline Microrganismos & CLO $_{30 \mu g}$ & TET $_{30} \mu \mathrm{g}$ & AMI $_{30 \mu \mathrm{g}}$ & Etanol $_{\text {abs }}$ \\
\hline 1 & $11,33 \pm 0,57$ & $16,66 \pm 0,57$ & $14,66 \pm 0,57$ & $\mathrm{ND}$ \\
2 & $21,33 \pm 0,57$ & $16,66 \pm 0,57$ & $22,66 \pm 0,57$ & $\mathrm{ND}$ \\
3 & $\mathrm{ND}$ & $\mathrm{ND}$ & $\mathrm{ND}$ & $\mathrm{ND}$ \\
4 & $15,66 \pm 0,57$ & $17,33 \pm 0,57$ & $27,66 \pm 0,57$ & $\mathrm{ND}$ \\
5 & $12,33 \pm 0,57$ & $11,33 \pm 0,57$ & $11,33 \pm 0,57$ & $\mathrm{ND}$ \\
6 & $\mathrm{ND}$ & $\mathrm{ND}$ & $16,33 \pm 0,57$ & $\mathrm{ND}$
\end{tabular}

1.Staphylococcus aureus; 2. Escherichia coli; 3.Proteus vulgaris; 4.Pseudomonas aeruginosa; 5.Shigella flexineri; 6.Klebsiella pneumoniae. CLO:Cloranfenicol; TET:Tetraciclina; AMI: Amicacina; ND:halo de inibição não foi detectável.

A eficiência do extrato de $S$. paniculatum pode ter sido devido à presença de alcalóides e taninos, já que, os primeiros são compostos azotados complexos, de natureza básica, capazes de produzir geralmente poderosos efeitos fisiológicos, e na maior parte dos casos, venenos vegetais muito ativos (Berti, 2009).

Como a atividade antimicrobiana dessas espécies deve estar relacionada ao teor de taninos encontrados nas raízes, podemos especular que $O$. hamiltonii possua teores de taninos menores que $S$. paniculatum.

Alguns mecanismos propostos, como desnaturação protéica, inibição enzimática e desintegração da membrana ocasionam uma provável interação entre os componentes do extrato, acarretando em sinergismo e/ou antagonismo (Janssen, 1989). Na espécie Eucalypus dives, foi observado que o teste frente a alguns microorganismos isolados, o óleo essencial total e fracionado mostrou sinergismo e/ou antagonismo, promovendo maior e/ou menor atividade 
antimicrobiana (Delasquis et al., 2002).

Estudos anteriores avaliaram o efeito in vitro do extrato etanólico raiz de Solanum paniculatum sobre ovos e larvas de nematóides gastrintestinais de caprinos, onde se observou que quanto maior a diluição do extrato menor o número de ovos viáveis, não havendo diferença significativa entre $25 \%$ e $50 \%$, sendo esta última a que deferiu estatisticamente das outras diluições apresentando maior número de larvas inviáveis, talvez devido a melhor aderência do extrato as larvas, demonstrando a ação ovicida e larvicida (Cordeiro, 2008).

Os halos analisados dos antibióticos Cloranfenicol, Tetraciclina (Tabela 2) demonstraram pouca eficiência nas cepas de Proteus vulgaris, $P$. aeruginosa e $K$. pneumoniae, mostrando-se resistentes. $\mathrm{O}$ antibiótico Amicacina apresentou boa resposta para inibição de todas as cepas.

Estes dados corroboram com os testes realizados com extrato hidroalcoólico da raiz de Operculina macrocarpa (L.) Urb., uma das espécies da família Convolvulaceae, não apresentaram atividade antimicrobiana frente aos microrganismos testados (Escherichia coli ATCC 25922, Bacillus subtilis ATCC 9372, Staphylococcus aureus ATCC 25923, Pseudomonas aeruginosa ATCC 27853 e Candida albicans ATCC 10231) (Michelin, 2005).

É importante destacar que Pérez-Amador et al. (1998) avaliaram a atividade antibacteriana das resinas de quatro espécies da família Convolvulaceae (Merremia tuberosa (L.) Rendle, Merremia dissecta (Jacq.) Hallier f., Operculina pinnatifida (Kunth) O'Donell e Turbina corymbosa (L.) Raf.) contra Escherichia coli e Bacillus subtilis em diferentes concentrações (10, 20 e $\left.30 \mathrm{mg} \mathrm{mL}^{-1}\right)$. Os resultados mostraram que as resinas das duas espécies de Merremia mostraram pequena atividade antibacteriana, e nenhuma atividade foi observada com $O$. pinnatifida e T. corymbosa.

Nascimento et al. (2006) relataram a atividade antimicrobiana in vitro de extratos vegetais de Solanum paniculatum Lam., sobre o crescimento de Ralstonia solanacearum e demonstraram que os solventes utilizados (acetona, clorofórmio, diclorometano e etanol 85\%) na preparação dos extratos de jurubeba, somente o etanol $85 \%$ mostrou capacidade inibitória sobre a cepa bacteriana por remover as substâncias da planta que foram capazes de interferir no crescimento bacteriano. Os halos de inibição ocorreram em torno dos discos impregnados com extratos etanólicos nas maiores concentrações de 100, 125 e $150 \mathrm{mg} \mathrm{mL}^{-1}$, com diâmetros de 2,6; 3,0 e 3,4 $\mathrm{mm}$, respectivamente. Dados corroboram com os apresentados neste experimento, onde o etanol, solvente utilizado, conseguiu extrair os princípios ativos dos extratos das plantas analisadas.

Os resultados da determinação da concentração inibitória mínima para Solanum paniculatum indicam que essa espécie apresenta moderada atividade antimicrobiana por apresentar um CIM para duas linhagens Gram-negativas (CIM>512) e uma Gram-positiva (CIM>256).

A maioria das plantas do gênero Solanum apresenta alcalóides esteroidais e saponinas esteroidais, glicoalcalóides e flavonóides que são importantes na defesa natural das plantas como metabólitos secundários; várias atividades biológicas são relatadas por possuir grande interesse na medicina tradicional, sendo aplicado como anabólicos, antiflogísticos, antialérgicos, contraceptivos, diuréticos, imunossupressores e tônicos (Mola et al., 1997; Cheng et al., 2008; Vieira et al., 2008).

TABELA 3. Classes de metabólitos secundários identificados no extrato bruto da raiz de S. paniculatum Lam. e da raiz da planta O. hamiltonii (G. Don) D. F. Austin \& Staples.

\begin{tabular}{lcc}
\hline & \multicolumn{2}{c}{ Espécies } \\
Classes de metabólitos secundários & Solanum paniculatum & Operculina hamiltonii \\
\hline Taninos & + & + \\
Fenóis & - & - \\
Flavanonas, Flavanóis, Xantonas, Flavanonóis & + & + \\
Flavanonas & + & + \\
Leucoantocianidinas, Catequinas & + & - \\
Antocianidinas, Antocianinas & - & - \\
Chanconas, Auronas & - & + \\
Alcalóides & + & - \\
Saponinas & + &
\end{tabular}

Rev. Bras. Pl. Med., Botucatu, v.12, n.2, p.227-233, 2010. 
Pelos resultados apresentados na Tabela 3 , as classes de substâncias revelaram que taninos flobabênicos, flavononóis, flavononas e alcalóides estão presentes em $S$. paniculatum e $O$. hamiltonii.

Estudos realizados por Vieira et al. (2008) relataram a presença de alcalóides do tipo glicoalcalóides além de compostos como glicídios, saponinas esteroidais e resinas em espécies de $S$. paniculatum.

\section{CONCLUSÃO}

As análises fitoquímicas realizadas neste trabalho revelaram que as espécies estudadas apresentam compostos pertencentes às classes dos alcalóides e taninos, que podem ser potencialmente ativos em modelos biológicos e farmacológicos.

Os ensaios antibacterianos indicaram sensibilidade do extrato da raiz de Solanum paniculatum contra $P$. aeruginosa, E. coli e S. aureus.

A espécie Operculina hamiltonii não obteve resultados satisfatórios frente às linhagens testadas demonstrando apenas possível sinergismo entre 0 extrato e o antibiótico.

Tendo em vista a grande diversidade de espécies nativas presentes no Brasil vêem-se o grande potencial fitoquímico armazenado à espera de novas pesquisas que comprovem o verdadeiro valor biológico das plantas medicinais, de baixo custo e de fácil acesso a população.

\section{AGRADECIMENTO}

Ao Conselho Nacional de Desenvolvimento Científico e Tecnológico (CNPq) pelo apoio financeiro. A Fundação Oswaldo Cruz- FIOCRUZ pela concessão das bactérias.

\section{REFERÊNCIA}

ALBUQUERQUE, U.P.; HANAZAKI, N. As pesquisas etnodirigidas na descoberta de novos fármacos de interesse médico e farmacêutico: fragilidades e perspectivas. Revista Brasileira de Farmacognosia, v.16, supl., p.678-89, 2006.

AURICCHIO, M.T.; BACCHI, E.M. Folhas de Eugenia uniflora L. (pitanga): propriedades farmacobotânicas, químicas e farmacológicas. Revista do Instituto Adolfo Lutz, v.62, 55-61, 2003.

BAUER, A.W.; PERRY, M.B.; KIRBY, W.M.M. Antibiotic susceptibility testing by a standardized single disk method. American Journal of Clinical Pathology, v.45, p.493-6, 1966.

BARBOSA-FILHO, J.M. et al. Natural products with antileprotic activity. Revista Brasileira de Farmacognosia, v.17, n.1, p.141-8, 2007.
BERTI, P. Substâncias das plantas medicinais. Disponível em: <http://www.professorberti. hpg.ig.com.br/ plant.htm>. Acesso em: 03 jan. 2009.

BRITO JUNIOR, L. Avaliação comparada da ação antihelmíntica da Batata de purga (Operculina hamiltonii (G. Don) D.F Austin \& Staples), do melão de são caetano (Momordica charantia L.) e do capim santo (Cymbopogon citratus (DC.) Stapf em caprinos naturalmente infectados. 2006. 55p. Dissertação (Mestrado em Zootecnia) - Universidade Federal de Campina Grande, Patos.

CHAGAS, A.C.S. Controle de parasitas utilizando extratos vegetais. Revista Brasileira de Parasitologia Veterinária, v.13, supl. 1, p.156-60, 2004.

CHENG, F.; LI, X.; WANG, J.Z. A new alkaloid from Solanum cathayanum. Chinese Chemical Letters, v.19, n.1, p.6870. 2008.

CORDEIRO, L.N. Efeito in vitro de extratos etanólicos da raiz de jurubeba (Solanum paniculatum L.) e das folhas de melão-de-são-caetano (Momordica charantia L.) sobre ovos e larvas de nematóides gastrintestinais de caprinos. 2008. 66p. Dissertação (Mestrado em Zootecnia) - Universidade Federal de Campina Grande, Patos.

DELASQUIS, P.J. et al. Antimicrobial activity of individual and mixed fractions of dill, cilandro, coriander and eucalyptus essential oils. Food Microbiology, v.74, p.10119, 2002.

FORNI-MARTINS, E.R.; MARQUES, M.C.M.; LEMES, M.R. Biologia floral e reprodução de Solanum paniculatum $L$. (Solanaceae) no estado de São Paulo, Brasil. Revista Brasileira Botânica, v.21, n.2, p.117-24, 1998.

HAVSTEEN, B. Flavonoids, a class of natural products of high pharmacological potency. Biochemical pharmacology, v.32, n.7, p.1141-8, 1983.

JANSSEN, A.M. Antimicrobial activities of essential oils: pharmacognostical study. 1989. 181p. Tese (Doctor aan de Rijksuniversiteit te Leiden) - Faculteit der Wiskunde en Natuurwetenschappen.

KREUGER, M.R.O. et al. The influence of the essential oil of Melaleuca alternifolia on the healing of infected dental alveoli: a histological study in rats. Revista Brasileira de Farmacognosia, v.17, n.3, p.349-55, 2007. MATOS, F.J.A. Introdução a fitoquímica experimental. 2.ed. Fortaleza: UFC, 1997. 141p.

MARTINS, E.R. et al. Plantas medicinais. Viçosa: UFV, 2000. p.178.

MESIA-VELA, S. et al. Solanum paniculatum L. (Jurubeba): Potent inhibitor of gastric acid secretion in mice. Phytomedicine, v.9, n.6, p.508-14, 2002.

MICHELIN, D.C. Caracterização fitoquímica e ensaios biológicos de Operculina macrocarpa (L.) Urb. (Convolvulaceae). 2004. 112p. Dissertação (MestradoÁrea de concentração em Ciências Farmacêuticas) Departamento de Farmácia, UNESP, Araraquara.

MOLA, J.L. et al. Solasodina em espécies de Solanum do cerrado do Distrito Federal. Química Nova, v.20, n.5, p.460-2, 1997.

NASCIMENTO, L.C.S.; SILVA, T.A.; ORLANDA, J.F.F. Atividade antimicrobiana in vitro de extratos vegetais de Solanum paniculatum L. sobre o crescimento de Ralstonia solanacearum. In: CONGRESSO BRASILEIRO DE QUÍMICA, 46., 2006, Salvador. Anais eletrônicos... 
Salvador: CESI/UEMA, 2006.

OLIVEIRA, F.Q. et al. Espécies vegetais indicadas na odontologia. Revista Brasileira de Farmacognosia, v.17, n.3, p.466-76, 2007a.

OLIVEIRA, R.A.G. et al. Interference of Plectranthus amboinicus (Lour.) Spreng essential oil on the antiCandida activity of some clinically used antifungals. Revista Brasileira de Farmacognosia, v.17, n.2, p.18690, 2007b.

PAZHANI, G.P. et al. Clonal multidrug-resistant Shigella dysenteriae Type 1 strains associated with epidemic and sporadic dysenteries in Eastern India. Antimicrobial Agents Chemotherapy, v.48, n.2, p.681-4, 2004.

PEREDA-MIRANDA, R.; TAKETA, A.T.C.; VILLATOROVERA, R.A. Alucinógenos naturais: etnobotânica e psicofarmacologia. In: SIMÕES, C.M.O. et al. Farmacognosia: da planta ao medicamento. 5.ed. Florianópolis: Editora da UFSC, 2003. p.919-58.

PÉREZ-AMADOR, M.C. et al. Resins of four species of Convolvulaceae and their allelopatic potencial. International Journal of Experimental Botany, v.62, n.1/ 2, p.195-8, 1998.

PRATES, M.V.; BOLCH, J.C. Peptídeos antimicrobianos: uma alternativa no combate a microrganismos resistentes. Biotecnologia: Ciência e Desenvolvimento, v.17, p.30-6, 2000.

RODRIGUES, A.B. et al. Sensibilidade dos nematóides gastrintestinais de caprinos a anti-helmínticos na mesorregião do Sertão Paraibano. Pesquisa Veterinária Brasileira, v.27, n.4, p.162-6, 2007.

SANTOS, A.P.L. Estudo fitoterápico da planta Solanum paniculatum L. (Jurubeba) em ovinos naturalmente infectados por nematóides gastrintestinais no sertão paraibano. 2007. 59p. Dissertação (Mestrado em Zootecnia) - Universidade Federal de Campina Grande, Patos.

SILVA, J.G. et al. Atividade antimicrobiana do extrato de Anacardium occidentale Linn. em amostras multiresistentes de Staphylococcus aureus. Revista Brasileira Farmacognosia, v.17, p.572-7, 2007.

SIMÕES, C.O. et al. Farmacognosia: da planta ao medicamento. 2.ed. Porto Alegre: Universidade Federal do Rio Grande do Sul, 2000, p.1104.

SIMÕES, C.C.;ARAÚJO, D.B.;ARAÚJO, R.P.C. Estudo in vitro e in vivo da ação de diferentes concentrações de extratos de própolis frente aos microrganismos presentes na saliva de humanos. Revista Brasileira Farmacognosia, v.18, p.84-9, 2008.

VIEIRA, P.M.; VIEIRA, A.; CHEN, L.C. Avaliação das atividades genotóxica dos frutos de Solanum paniculatum L. pelo teste do micronúcleo em camundongo. In: CONGRESSO DE GENÉTICA DO CENTRO-OESTE, 1., 2008, Brasília. Anais eletrônicos... Brasília: UnB, 2008.

WORLD HEALDTH ORGANIZATION. Report on infectious diseases. Geneva: WHO, 2002. 